\title{
Prognostic and clinicopathological significance of Gankyrin overexpression in cancers: evidence from a meta-analysis
}

This article was published in the following Dove Press journal:

OncoTargets and Therapy

4 April 2016

Number of times this article has been viewed

\author{
Xiaotong Zhaol,* \\ Fangzhou $\mathrm{Liu}^{2}$,* \\ Yuan Zhang ${ }^{2}$ \\ Peihua Li' \\ 'Department of Otolaryngology, \\ Affiliated Hospital of XuZhou Medical \\ College, Xuzhou, ${ }^{2}$ Department of \\ Otolaryngology, The Affiliated Cancer \\ Hospital, Nanjing Medical University, \\ Nanjing, Jiangsu, People's Republic \\ of China \\ *These authors contributed equally \\ to this work
}

\begin{abstract}
Many studies have indicated that Gankyrin is a promising and novel prognostic tumor biomarker. However, the results of different studies remained controversial. Hence, a meta-analysis was undertaken to investigate the association between Gankyrin expression and cancer prognosis. Eligible studies were identified by searching the electronic databases PubMed, Embase, and Cochrane Library up to November 2015. Prognostic value of Gankyrin expression was evaluated by hazard ratio with $95 \%$ confidence interval (CI). Meanwhile, relative risk (RR) with 95\% CI was used to assess the effects of Gankyrin expression on clinicopathological parameters. In total, ten studies with 1,326 patients were included for final analysis. A significant association was found between Gankyrin overexpression and poorer overall survival in patients with cancer (hazard ratio $=1.73,95 \% \mathrm{CI}: 1.29-2.31, P=0.000$ ). In the subgroup analysis, the association was also detected in Chinese patients and patients with cancers of the digestive system. The pooled RR indicated that Gankyrin overexpression was related to advanced tumor-node-metastasis stage ( $\mathrm{RR}=0.72,95 \% \mathrm{CI}$ : $0.60-0.86, P=0.000)$, positive lymph node metastasis ( $\mathrm{RR}=1.66,95 \% \mathrm{CI}: 1.41-1.94, P=0.000)$, and distant metastasis $(\mathrm{RR}=1.43,95 \%$ CI: $1.20-1.70, P<0.000)$. The meta-analysis demonstrated that Gankyrin is a novel biomarker for predicting cancers, especially digestive system cancers, and is more suitable for predicting cancer prognoses in Asians.
\end{abstract}

Keywords: Gankyrin, cancer, prognosis, meta-analysis

\section{Introduction}

Gankyrin protein (also named as PSMD10, p28[Gank], or p28) is a small protein $(25 \mathrm{kDa})$. It was initially identified and characterized as the p28 component of a regulatory subunit of the $26 \mathrm{~S}$ proteasome in $1998 .{ }^{1}$ Gankyrin is highly conserved in all mammals., "Gann" means cancer in Japanese, and ankyrin is functional domain that is involved in protein-protein interactions. Gankyrin protein contains two typical domains including seven ankyrin repeats and Rb-recognition motif (LXCXE), and the name of Gankyrin was derived from these factors. ${ }^{4-6}$ Previous studies showed that Gankyrin enhances cancer cell proliferation through interaction with p53 and Rb, ${ }^{7-9}$ and the aberrant expression of Gankyrin is associated with cancer progression and poor prognoses. Although many clinical studies suggested that the overexpression of Gankyrin was a predictor for worse outcome in cancers, ${ }^{10-17}$ some other conflicting conclusions were arrived. ${ }^{18,19}$ Therefore, the prognostic value of Gankyrin overexpression remains controversial. To overcome the limitation of the single study, this metaanalysis was conducted to investigate the relationship between Gankyrin expression and its prognostic value in cancers. 


\section{Materials and methods}

\section{Search strategy}

A systematic literature search of the databases PubMed, Embase, and Cochrane Library was performed with the following strategy: "Gankyrin" OR "p28" OR "p28Gank" OR "PSMD10" AND "prognosis" OR "prognostic" OR "survival" OR "outcome" AND "cancer" OR "carcinoma" OR "neoplasm" OR "tumor" OR "malignant" up to November 2015. To explore additional studies, we also inspected the references of the included studies. The eligible reports were identified independently by two investigators (Zhao and Liu).

\section{Inclusion criteria}

Eligible studies have to meet the following inclusion criteria: 1) had to evaluate the Gankyrin expression in human cancer tissues; 2) had to evaluate the association between Gankyrin expression and cancer prognosis; and 3) had to have sufficient information to estimate the hazard ratios (HRs) with $95 \%$ confidence intervals (CIs). The exclusion criteria were as follows: 1) reviews, case reports, letters, and conference abstracts and 2) overlapping data. The flow diagram of study selection is presented in Figure 1.

\section{Data extraction}

Data from eligible studies were extracted independently by two investigators (Zhao and Liu) according to the inclusion and exclusion criteria mentioned earlier.

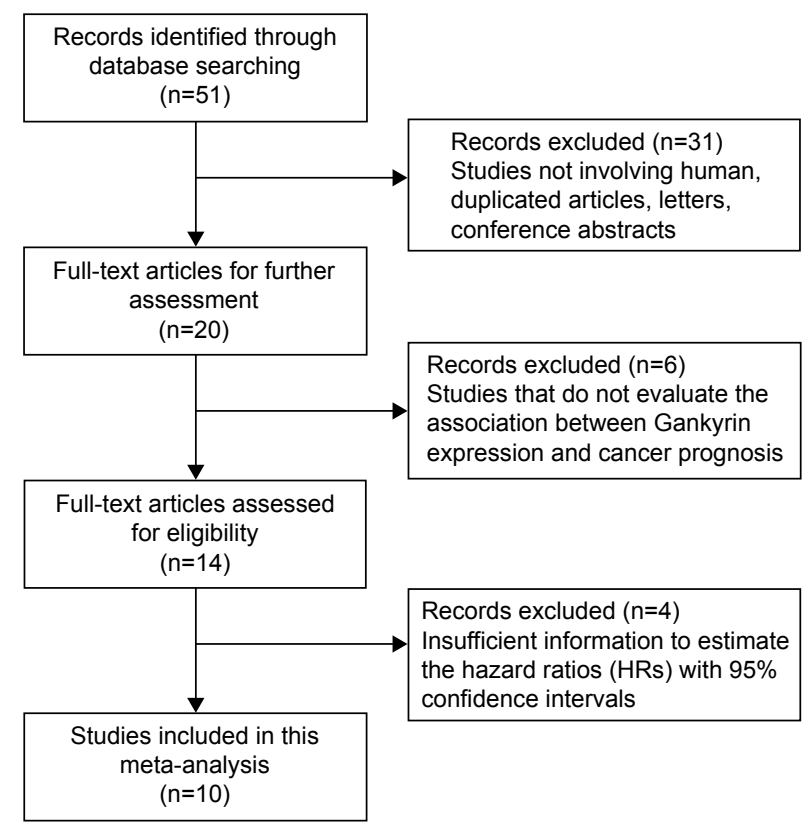

Figure I The flow diagram of study selection.
The following items were collected: first author's name, year of publication, nationality, number of cases, cancer type, detecting method (immunohistochemistry [IHC] or real-time polymerase chain reaction), cutoff value, HRs with corresponding 95\% CIs for overall survivals (OSs), and clinicopathological parameters. Any disagreements were settled by a third investigator (Li).

\section{Quality assessment}

The quality of included studies was assessed by two independent investigators (Zhao and Liu) on the basis of the Newcastle-Ottawa scale (NOS) system. ${ }^{20}$ NOS is a 9-point scoring system, and studies with an NOS score $\geq 6$ were regarded as high-quality studies.

\section{Statistical analysis}

HRs with their 95\% CIs were calculated to evaluate the association between Gankyrin expression levels and the cancer prognosis (OS). If available, we obtained data from article directly. If not, we calculated data from Kaplan-Meier curves. ${ }^{21}$ Meanwhile, the impact of Gankyrin expression on clinicopathological parameters was performed by relative risks (RRs) with their 95\% CIs. The heterogeneity among the included studies was checked by the chi-squared Q test. ${ }^{22}$ If the heterogeneity exists $\left(P<0.10\right.$ or $\left.I^{2}>50 \%\right)$, the randomeffects model was used; otherwise, the fixed-effects model was used. ${ }^{23}$ Subgroup analyses were conducted to explore the source of heterogeneity. Moreover, a sensitivity analysis was carried out to evaluate whether any single study could have effects on the pooled HRs by sequentially discarding individual studies. Egger's test and Begg's funnel plots were applied to assess publication biases. ${ }^{24}$ All statistical analyses were performed using Stata 12.0 (StataCorp LP, College Station, TX, USA). $P$-value $<0.05$ was considered statistically significant.

\section{Results}

\section{Study characteristics}

According to the search strategy, a total of 51 studies were selected after the initial search. All the studies were identified by the inclusion and exclusion criteria mentioned earlier. Finally, ten eligible studies, published from 2008 to 2015 , were included in this meta-analysis. The main characteristics of the eligible studies are summarized in Table 1. A total of 1,326 patients from the People's Republic of China, ${ }^{10,11,13-16,19}$ Japan, ${ }^{17,18}$ and Korea ${ }^{12}$ were involved. Of all the eligible studies, nine were in English language, ${ }^{10,12-19}$ whereas one was in Chinese ${ }^{11}$ (seven were 
Table I Main characteristics of eligible studies in this meta-analysis

\begin{tabular}{|c|c|c|c|c|c|c|c|c|}
\hline $\begin{array}{l}\text { First } \\
\text { author }\end{array}$ & Year & Case nationality & $\begin{array}{l}\text { Case } \\
\text { number }\end{array}$ & Cancer type & Method & Cutoff & $\begin{array}{l}\text { HR }(95 \% \mathrm{Cl}) \\
\text { for OS }\end{array}$ & $\begin{array}{l}\text { NOS } \\
\text { score }\end{array}$ \\
\hline Wang et al ${ }^{10}$ & 2015 & People's Republic of China & 166 & Non-small-cell lung cancer & $\mathrm{IHC}$ & Score $\geq 4$ & I.5। (1.02-2.24) & 8 \\
\hline Wu et al" & 2015 & People's Republic of China & 100 & Colorectal cancer & $\mathrm{IHC}$ & $5 \%$ & $3.21(1.01-10.17)$ & 7 \\
\hline Hwang et $\mathrm{al}^{12}$ & 2014 & Korea & 204 & Liposarcoma & $\mathrm{IHC}$ & Score $\geq 2$ & $2.21(1.22-4.00)$ & 6 \\
\hline Jing et $\mathrm{al}^{19}$ & 2014 & People's Republic of China & 193 & Hepatocellular carcinoma & $\mathrm{IHC}$ & Median & $1.24(0.85-1.82)$ & 8 \\
\hline Zheng et $\mathrm{al}^{13}$ & 2014 & People's Republic of China & 85 & Cholangiocarcinoma & $\mathrm{IHC}$ & Median & $2.11(1.13-3.93)$ & 8 \\
\hline Zheng et $\mathrm{al}^{14}$ & 2014 & People's Republic of China & 124 & Gastric cancer & RT-PCR & Median & $2.26(1.40-3.66)$ & 7 \\
\hline Yang et al ${ }^{15}$ & 2012 & People's Republic of China & 138 & Glioma cancer & $\mathrm{IHC}$ & Score $\geq 3$ & $2.50(1.07-5.84)$ & 8 \\
\hline Fu et $\mathrm{al}^{16}$ & 2011 & People's Republic of China & 201 & Hepatocellular carcinoma & $\mathrm{IHC}$ & Median & $1.74(1.15-2.66)$ & 7 \\
\hline Ortiz et $\mathrm{al}^{17}$ & 2008 & Japan & 72 & Esophageal cell carcinoma & $\mathrm{IHC}$ & $50 \%$ & $2.89(0.70-\mid 1.91)$ & 7 \\
\hline Umemura et al ${ }^{18}$ & 2008 & Japan & 43 & Hepatocellular carcinoma & $\mathrm{IHC}$ & $50 \%$ & $0.15(0.04-0.64)$ & 7 \\
\hline
\end{tabular}

Abbreviations: HR, hazard ratio; Cl, confidence interval; OS, overall survival; NOS, Newcastle-Ottawa scale; IHC, immunohistochemistry; RT-PCR, real-time polymerase chain reaction.

about digestive system cancers [hepatocellular cancer, colorectal cancer, esophageal cancer, gastric cancer, and cholangiocarcinoma cancer] and three were about other cancer types [non-small-cell lung cancer, glioma cancer, and liposarcoma]). IHC was the main method used to detect the Gankyrin expression in these studies, but in one study, it was detected by real-time polymerase chain reaction.

\section{Meta-analysis results \\ Gankyrin expression and OS}

As shown in Figure 2, Gankyrin overexpression was significantly associated with poor OS in cancers ( $\mathrm{HR}=1.73$,
95\% CI: $1.29-2.31, P=0.000)$. Owing to the heterogeneity detected in these studies $\left(P=0.019, I^{2}=54.6 \%\right)$, the randomeffects model was applied.

To explore the source of heterogeneity, subgroup analyses were performed by nationality, cancer type, detecting method, and cutoff value. In our subgroup analysis, a significant association between Gankyrin overexpression and poor OS was observed in the "People's Republic of China" subgroup (HR $=1.72,95 \%$ CI: 1.40-2.11, $P=0.000)$, "digestive system cancers" subgroup ( $\mathrm{HR}=1.62,95 \% \mathrm{CI}: 1.05-2.49, P=0.028$ ), "IHC" subgroup ( $\mathrm{HR}=1.66,95 \% \mathrm{CI}$ : $1.20-2.29, P=0.002)$, and "cutoff value median" subgroup (HR $=1.71,95 \% \mathrm{CI}$ : 1.29-2.27, $P=0.000$; Table 2).

\begin{tabular}{|c|c|c|c|}
\hline Study ID & & ES $(95 \% \mathrm{Cl})$ & Weight (\%) \\
\hline Wang et $\mathrm{al}^{10}$ & & $1.51(1.02-2.24)$ & 15.18 \\
\hline Wu et $\mathrm{al}^{11}$ & & $3.21(1.01-10.17)$ & 4.88 \\
\hline Hwang et al ${ }^{12}$ & & $2.21(1.22-4.00)$ & 11.19 \\
\hline Jing et $\left.a\right|^{19}$ & $\rightarrow$ & $1.24(0.85-1.82)$ & 15.45 \\
\hline Zheng et $\mathrm{al}^{13}$ & & $2.11(1.13-3.93)$ & 10.66 \\
\hline Zheng et $\mathrm{al}^{14}$ & & $2.26(1.40-3.66)$ & 13.35 \\
\hline Yang et al ${ }^{15}$ & & $2.50(1.07-5.84)$ & 7.52 \\
\hline Fu et $\mathrm{al}^{16}$ & $\longrightarrow$ & $1.74(1.15-2.66)$ & 14.63 \\
\hline Ortiz et $\mathrm{al}^{17}$ & & $2.89(0.70-11.91)$ & 3.50 \\
\hline Umemura et al ${ }^{18}$ & & $0.15(0.04-0.64)$ & 3.63 \\
\hline Overall $\left(I^{2}=54.6 \%, P=0.019\right)$ & & $1.73(1.29-2.31)$ & 100 \\
\hline
\end{tabular}

Figure 2 A forest plot of HR for the relationship between high Gankyrin expression and OS. Note: Weights are from random-effects analysis.

Abbreviations: $\mathrm{HR}$, hazard ratio; OS, overall survival; $\mathrm{ES}$, effect size; $\mathrm{Cl}$, confidence interval. 
Table 2 Main results of subgroup analyses

\begin{tabular}{|c|c|c|c|c|c|c|}
\hline \multirow[t]{2}{*}{ Categories } & \multirow[t]{2}{*}{ Studies (n) } & \multirow{2}{*}{$\begin{array}{l}\text { Number } \\
\text { of patients }\end{array}$} & \multirow{2}{*}{$\begin{array}{l}\text { HR }(95 \% \mathrm{Cl}) \\
\text { for OS }\end{array}$} & \multicolumn{3}{|c|}{ Heterogeneity } \\
\hline & & & & $I^{2}(\%)$ & $\boldsymbol{P}_{\mathrm{h}}$ & $P$-value \\
\hline OS & 10 & 1,326 & $1.73(1.29-2.31)$ & 54.60 & 0.019 & 0.000 \\
\hline \multicolumn{7}{|l|}{ Nationality } \\
\hline People's Republic of China & 7 & $\mathrm{I}, 007$ & $1.72(1.40-2.11)$ & 11.30 & 0.344 & 0.000 \\
\hline Japan & 2 & 115 & $0.66(0.04-11.91)$ & 88.30 & 0.003 & 0.776 \\
\hline \multicolumn{7}{|l|}{ Cancer type } \\
\hline Digestive system cancers & 7 & 818 & $1.62(1.05-2.49)$ & 66.30 & 0.007 & 0.028 \\
\hline \multicolumn{7}{|l|}{ Methods } \\
\hline $\mathrm{IHC}$ & 9 & 1,202 & $1.66(1.20-2.29)$ & 56.00 & 0.02 & 0.002 \\
\hline \multicolumn{7}{|l|}{ Cutoff value } \\
\hline Median & 4 & 603 & I.7I (1.29-2.27) & 32.40 & 0.218 & 0.000 \\
\hline
\end{tabular}

Abbreviations: $\mathrm{HR}$, hazard ratio; $\mathrm{Cl}$, confidence interval; OS, overall survival; $P_{\mathrm{h}}, P_{\mathrm{h}}$

; IHC, immunohistochemistry.

\section{Gankyrin expression and clinicopathological} parameters

As shown in Figure 3 and Table 3, increased Gankyrin was significantly associated with poorer tumor-nodemetastasis $(\mathrm{TNM})$ stage $(\mathrm{RR}=0.72,95 \% \mathrm{CI}: 0.60-0.86$, $P=0.000)$, positive lymph node metastasis ( $\mathrm{RR}=1.66,95 \%$ CI: $1.41-1.94, P=0.000)$, and positive distant metastasis (RR $=1.43,95 \% \mathrm{CI}: 1.20-1.70, P=0.000)$, but not with sex $(P=0.271)$ and histological grade $(P=0.070)$. Owing to insufficient data, we did not detect the relationship between
Gankyrin overexpression and other clinicopathological parameters.

\section{Sensitivity analysis}

Sensitivity analysis showed no significant changes in HRs when any individual study was discarded (Figure 4).

\section{Publication bias}

Egger's test and Begg's funnel plots were applied to assess publication biases. The $P$-value of Egger's test for

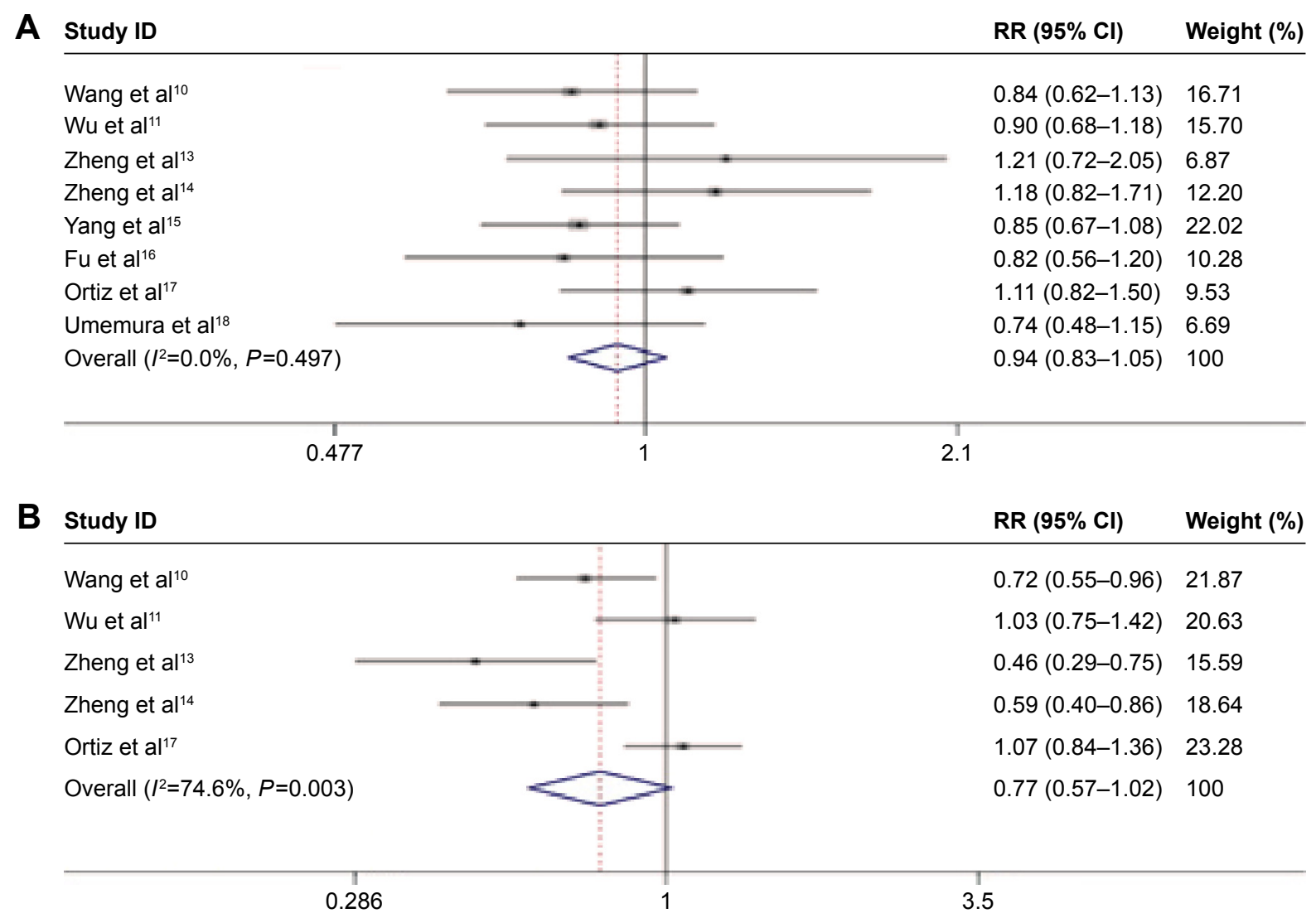

Figure 3 (Continued) 


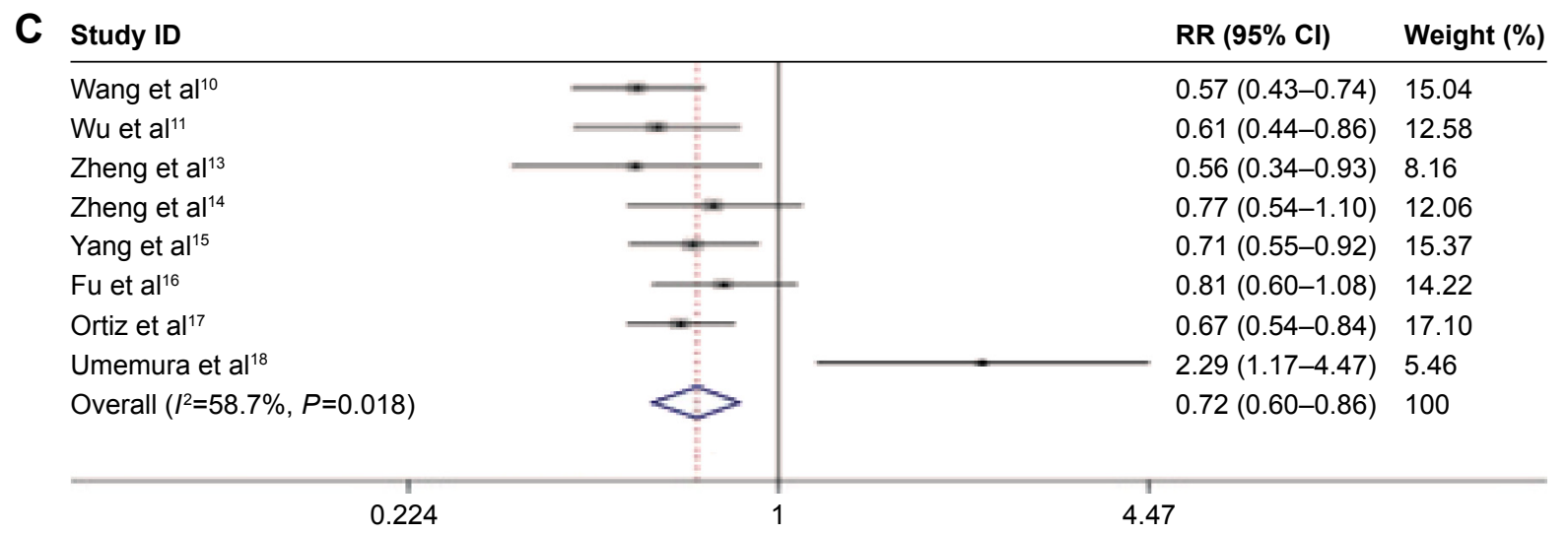

\begin{tabular}{|c|c|c|}
\hline Study ID & $\mathrm{RR}(95 \% \mathrm{Cl})$ & Weight (\%) \\
\hline Wang et al ${ }^{10}$ & $1.74(1.27-2.39)$ & 26.77 \\
\hline Wu et al ${ }^{11}$ & $1.50(1.10-2.06)$ & 21.68 \\
\hline Zheng et al ${ }^{13}$ & $1.79(1.03-3.11)$ & 10.45 \\
\hline Zheng et al ${ }^{14}$ & $1.68(1.17-2.43)$ & 19.68 \\
\hline Ortiz et al ${ }^{17}$ & $1.61(1.18-2.19)$ & 21.42 \\
\hline Overall $\left(I^{2}=0.0 \%, P=0.965\right)$ & $1.66(1.14-1.94)$ & 100 \\
\hline
\end{tabular}

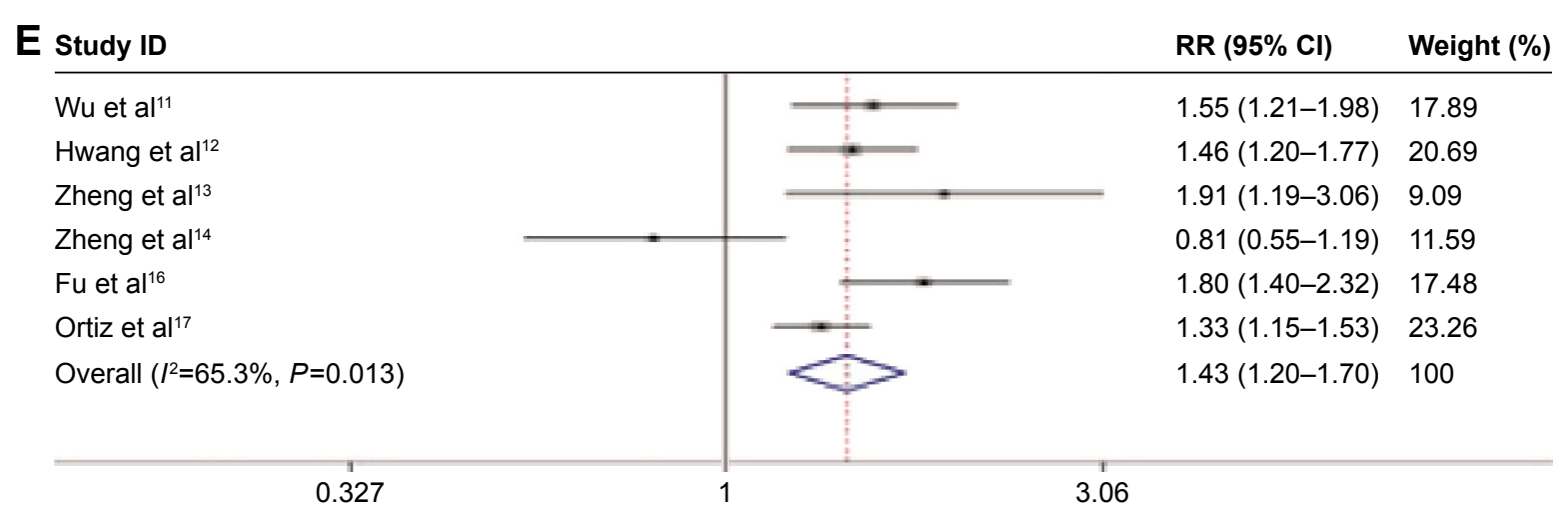

Figure 3 A forest plot of Gankyrin expression and clinicopathological parameters.

Notes: The relationship between (A) high Gankyrin expression and sex, (B) high Gankyrin expression and histological grade, (C) high Gankyrin expression and TNM stage,

(D) high Gankyrin expression and lymph node metastasis, and (E) high Gankyrin expression and distant metastasis. Weights are from random-effects analysis.

Abbreviations: TNM, tumor-node-metastasis; RR, relative risk; $\mathrm{Cl}$, confidence interval.

Table 3 Meta-analysis: RR value and $95 \% \mathrm{Cl}$ of clinicopathological parameters

\begin{tabular}{|c|c|c|c|c|c|c|c|}
\hline \multirow[t]{2}{*}{ Categories } & \multirow[t]{2}{*}{ Studies (n) } & \multirow{2}{*}{$\begin{array}{l}\text { Number } \\
\text { of patients }\end{array}$} & \multirow[t]{2}{*}{$\operatorname{RR}(95 \% \mathrm{Cl})$} & \multicolumn{4}{|c|}{ Heterogeneity } \\
\hline & & & & $I^{2}(\%)$ & $\boldsymbol{P}_{\mathrm{h}}$ & $P$-value & Model \\
\hline \multicolumn{8}{|l|}{ Sex } \\
\hline Male vs female & 8 & 960 & $0.94(0.83-1.05)$ & 0.00 & 0.497 & $0.27 \mathrm{I}$ & Fixed effects \\
\hline \multicolumn{8}{|l|}{ Histological grade } \\
\hline Well, moderate vs poor & 5 & 570 & $0.77(0.57-1.02)$ & 74.60 & 0.003 & 0.070 & Random effects \\
\hline \multicolumn{8}{|l|}{ TNM stage } \\
\hline I, II vs III, IV & 8 & 960 & $0.72(0.60-0.86)$ & 58.70 & 0.018 & 0.000 & Random effects \\
\hline \multicolumn{8}{|l|}{ Lymph node metastasis } \\
\hline$+v s-$ & 5 & 578 & $1.66(1.41-1.94)$ & 0.00 & 0.965 & 0.000 & Fixed effects \\
\hline \multicolumn{8}{|l|}{ Distant metastasis } \\
\hline$+v s-$ & 6 & 815 & I.43 (I.20-I.70) & 65.30 & 0.013 & 0.000 & Random effects \\
\hline
\end{tabular}

Abbreviations: $\mathrm{RR}$, relative risk; $\mathrm{Cl}$, confidence interval; $P_{\mathrm{h}}, P_{\text {heterogeneity }} ; \mathrm{TNM}$, tumor-node-metastasis. 


\section{Meta-analysis estimates, given named study is omitted}

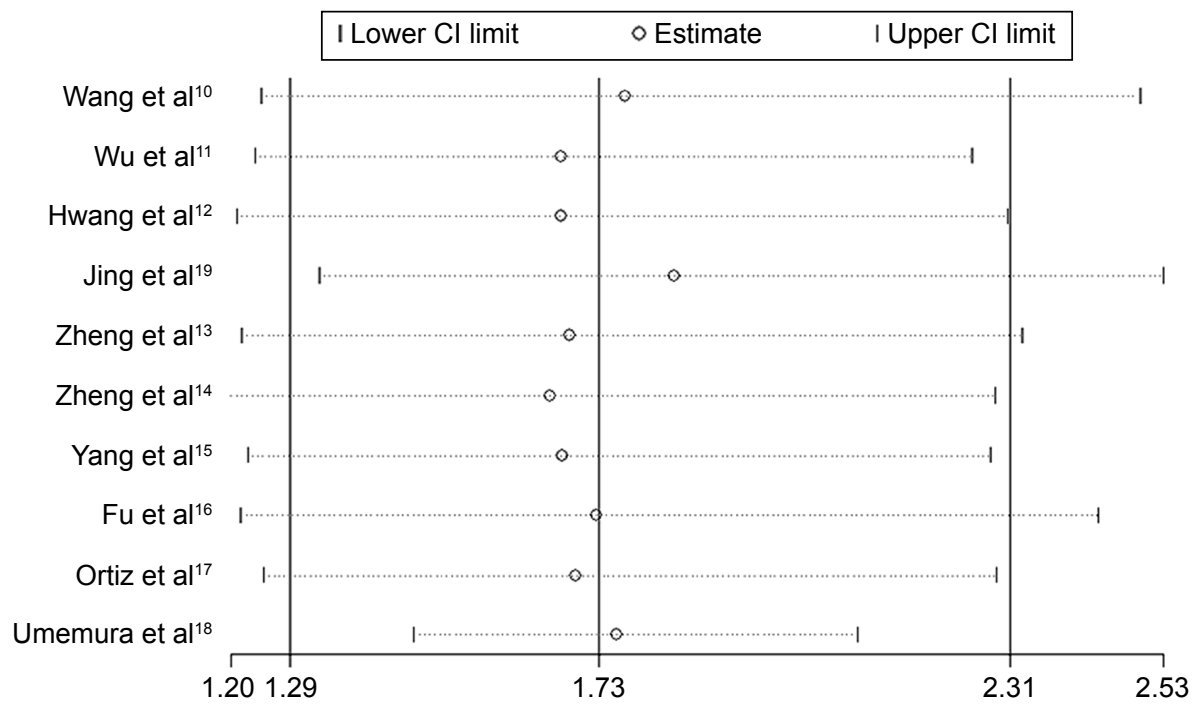

Figure 4 Sensitivity analysis for overall survival. Abbreviation: $\mathrm{Cl}$, confidence interval.

OS $(P=0.946)$ indicated no publication bias among these studies. The symmetric funnel plots also suggested no evidence of publication bias in this meta-analysis (Figure 5). Because of the limited number of included studies $(n<10)$, the publication bias for clinicopathological parameters was not assessed.

\section{Discussion}

The Gankyrin gene is located on human chromosome $\mathrm{Xq} 22.3$ and encodes a protein with seven ankyrin repeats, which is required for protein-protein interactions. ${ }^{1,25}$ Gankyrin was considered to enhance tumor onset and progression by modulating the phosphorylation of $\mathrm{Rb}$ and the ubiquitylation of p53. ${ }^{8}$ In 2000, Higashitsuji et al identified

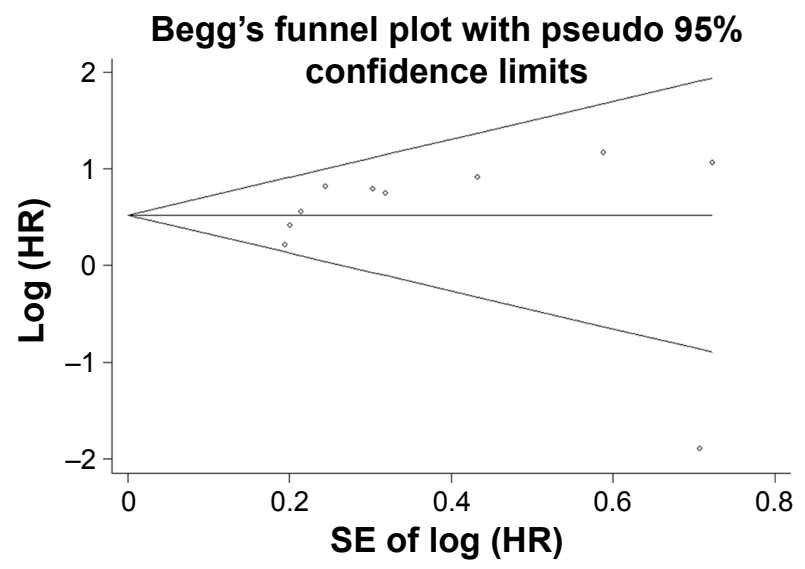

Figure 5 Begg's funnel plot of Gankyrin expression and OS in patients with cancer. Abbreviations: OS, overall survival; HR, hazard ratio; SE, standard error. the Gankyrin as a gene that was consistently overexpressed in hepatocellular cancer and then opened the investigative prolog in Gankyrin expression in malignant tumor. In the following years, Gankyrin have attracted much attention, especially in Asia. It was reported that Gankyrin was negatively or weakly expressed in normal tissues, but was highly expressed in various cancers. ${ }^{10-19,26-30}$ Although the focus area of the research is in digestive system cancers, the role of Gankyrin in other malignant tumors has received increasing attention in recent years. Several studies have found that Gankyrin might be an important prognostic marker for malignant cancers. ${ }^{10-17}$ However, some conflicting conclusions have been reported. Umemura et $\mathrm{al}^{18}$ came to the opposite conclusion that positive expression of Gankyrin might predict a better prognosis in hepatocellular cancer. Moreover, an insignificant result was obtained by Jing et al. ${ }^{19}$ Since the prognostic value of Gankyrin expression remained inconclusive, a meta-analysis was carried out to address the controversial issue.

To the best of our knowledge, the present analysis is the first meta-analysis to evaluate the role of Gankyrin as a cancer prognostic. Here, we identified ten studies including 1,326 cases. We observed that Gankyrin overexpression was associated with a poor prognosis in patients with cancer $(\mathrm{HR}=1.73,95 \% \mathrm{CI}: 1.29-2.31, P=0.000)$. Additionally, the results revealed that elevated Gankyrin expression was related to TNM stage, lymph node metastasis, and distant metastasis. Based on the results, Gankyrin might act as 
a reliable biomarker for cancers and could help us to predict clinical outcomes of patients with cancer.

To explain the heterogeneity in OS, subgroup analyses were performed. It revealed that a high Gankyrin expression was related to poor prognosis in Chinese patients (HR $=1.72,95 \% \mathrm{CI}: 1.40-2.11, P=0.000)$, but was not statistically significant in Japanese patients ( $\mathrm{HR}=0.66$, 95\% CI: 0.04-11.91, $P=0.776$ ). Because most of patients enrolled in this meta-analysis were Chinese, it demonstrated that Gankyrin may play a greater role in Chinese patients. We deduced that the discrepancy might be caused by genotype difference and the small sample size (only two studies with 115 Japanese patients were included). The results might not be representative, and more large size studies are necessary to enhance the reliability of the conclusion. The results also indicated that elevated Gankyrin expression was significantly associated with poor OS in digestive system cancers $(\mathrm{HR}=1.62,95 \% \mathrm{CI}: 1.05-2.49, P=0.028)$. In terms of methods for detection, we found that IHC was widely applied and considered as an effective method (HR $=1.66$, 95\% CI: $1.20-2.29, P=0.002)$. In addition, we found that the heterogeneity of OS reduced in the "median" subgroup. This may be because different standards of cutoff values caused the heterogeneity. Significant heterogeneity was also found for the association between evaluated Gankyrin with histological grade, TNM stage, and distant metastasis. The random-effects model was applied. In view of the limited number of studies ( $n=5,8,6$, respectively), the subgroup analyses were not performed. The heterogeneity could be explained by the differences in characteristics of patients, detecting methods, cutoff values, antibodies, and so on. Therefore, to increase the reliability of the conclusions, more homogeneous samples are needed.

Although efforts were made to conduct this meta-analysis, some limitations should be acknowledged. First, most of the included studies focused on the digestive system cancers, and the small number of the studies focusing on each type of cancer might weaken our conclusions; thus, more efforts are needed in the future. Second, all the studies included were from Asian countries; hence, our conclusion might be more applicable to the Asian populations. It is difficult to make a reliable conclusion for other regions. Third, if the study did not provide HRs with 95\% CIs, we had to extract data from Kaplan-Meier curves, and the calculated data might be less reliable. Fourth, although most of the studies detected the Gankyrin expression by IHC, the different antibody concentrations and the variable cutoff value might influence the results.

\section{Conclusion}

In conclusion, the meta-analysis indicated that Gankyrin overexpression was significantly associated with poor prognosis and might be a promising biomarker in predicting clinical outcomes for cancer patients, especially patients with cancers of the digestive system. Further clinical researches are needed to strengthen our conclusions and confirm the precise prognostic value of Gankyrin in cancers.

\section{Disclosure}

The authors report no conflicts of interest in this work.

\section{References}

1. Hori T, Kato S, Saeki M, et al. cDNA cloning and functional analysis of p28 (Nas6p) and p40.5 (Nas7p), two novel regulatory subunits of the 26S proteasome. Gene. 1998;216(1):113-122.

2. Yuan C, Li J, Mahajan A, Poi MJ, Byeon IJ, Tsai MD. Solution structure of the human oncogenic protein gankyrin containing seven ankyrin repeats and analysis of its structure-function relationship. Biochemistry. 2004;43(38):12152-12161.

3. Manjasetty BA, Quedenau C, Sievert V, et al. X-ray structure of human gankyrin, the product of a gene linked to hepatocellular carcinoma. Proteins. 2004;55(1):214-217.

4. Chen Y, Li HH, Fu J, et al. Oncoprotein p28 GANK binds to RelA and retains NF-kappaB in the cytoplasm through nuclear export. Cell Res. 2007;17(12):1020-1029.

5. LiJ, Tsai MD. Novel insights into the INK4-CDK4/6-Rb pathway: counter action of gankyrin against INK4 proteins regulates the CDK4-mediated phosphorylation of Rb. Biochemistry. 2002;41(12):3977-3983.

6. Higashitsuji H, Itoh K, Nagao T, et al. Reduced stability of retinoblastoma protein by gankyrin, an oncogenic ankyrin-repeat protein overexpressed in hepatomas. Nat Med. 2000;6(1):96-99.

7. Higashitsuji H, Higashitsuji H, Itoh K, et al. The oncoprotein gankyrin binds to MDM2/HDM2, enhancing ubiquitylation and degradation of p53. Cancer Cell. 2005;8(1):75-87.

8. Dawson S, Higashitsuji H, Wilkinson AJ, Fujita J, Mayer RJ. Gankyrin: a new oncoprotein and regulator of $\mathrm{pRb}$ and $\mathrm{p} 53$. Trends Cell Biol. 2006; 16(5):229-233.

9. Iwai A, Marusawa $\mathrm{H}$, Kiuchi T, et al. Role of a novel oncogenic protein, gankyrin, in hepatocyte proliferation. $J$ Gastroenterol. 2003;38(8): 751-758.

10. Wang WP, Yan XL, Li WM, et al. Clinicopathologic features and prognostic implications of Gankyrin protein expression in non-small cell lung cancer. Pathol Res Pract. 2015;211(12):939-947.

11. Wu Q, He F, Yang P, et al. Association of gankyrin protein expression in human colorectal cancer with postoperative prognosis. Chin J Gastrointest Surg. 2015;18(6):611-615.

12. Hwang JA, Yang HM, Hong DP, et al. Gankyrin is a predictive and oncogenic factor in well-differentiated and dedifferentiated liposarcoma. Oncotarget. 2014;5(19):9065-9078.

13. Zheng T, Hong X, Wang J, et al. Gankyrin promotes tumor growth and metastasis through activation of IL-6/STAT3 signaling in human cholangiocarcinoma. Hepatology. 2014;59(3):935-946.

14. Zheng JY, Hu H, Du JJ, Li XH, Zhao QC. p28GANK is a novel marker for prognosis and therapeutic target in gastric cancer. Mol Biol. 2014; 48(1):84-90.

15. Yang Y, Zhang C, Li L, et al. Up-regulated oncoprotein P28GANK correlates with proliferation and poor prognosis of human glioma. World J Surg Oncol. 2012;10:169.

16. Fu J, Chen Y, Cao J, et al. p28GANK overexpression accelerates hepatocellular carcinoma invasiveness and metastasis via phosphoinositol 3-kinase/AKT/hypoxia-inducible factor-1alpha pathways. Hepatology. 2011;53(1):181-192. 
17. Ortiz CM, Ito T, Tanaka E, et al. Gankyrin oncoprotein overexpression as a critical factor for tumor growth in human esophageal squamous cell carcinoma and its clinical significance. Int J Cancer. 2008;122(2): 325-332.

18. Umemura A, Itoh $Y$, ItohK, etal. Association of gankyrin protein expression with early clinical stages and insulin-like growth factor-binding protein 5 expression in human hepatocellular carcinoma. Hepatology. 2008; 47(2):493-502.

19. Jing H, Zhang G, Meng L, Meng Q, Mo H, Tai Y. Gradually elevated expression of Gankyrin during human hepatocarcinogenesis and its clinicopathological significance. Sci Rep. 2014;4:5503.

20. Stang A. Critical evaluation of the Newcastle-Ottawa scale for the assessment of the quality of nonrandomized studies in meta-analyses. Eur J Epidemiol. 2010;25(9):603-605.

21. Tierney JF, Stewart LA, Ghersi D, Burdett S, Sydes MR. Practical methods for incorporating summary time-to-event data into meta-analysis. Trials. 2007;8:16.

22. Higgins JP, Thompson SG, Deeks JJ, Altman DG. Measuring inconsistency in meta-analyses. BMJ. 2003;327(7414):557-560.

23. Lau J, Ioannidis JP, Schmid CH. Quantitative synthesis in systematic reviews. Ann Intern Med. 1997;127(9):820-826.
24. Egger M, Davey Smith G, Schneider M, Minder C. Bias in meta-analysis detected by a simple, graphical test. BMJ. 1997;315(7109):629-634.

25. Krzywda S, Brzozowski AM, Higashitsuji H, et al. The crystal structure of gankyrin, an oncoprotein found in complexes with cyclin-dependent kinase 4, a 19 S proteasomal ATPase regulator, and the tumor suppressors Rb and p53. J Biol Chem. 2004;279(2):1541-1545.

26. Bai Z, Tai Y, Li W, et al. Gankyrin activates IL-8 to promote hepatic metastasis of colorectal cancer. Cancer Res. 2013;73(14):4548-4558.

27. Liu Y, Zhang J, Qian W, et al. Gankyrin is frequently overexpressed in cervical high grade disease and is associated with cervical carcinogenesis and metastasis. PLoS One. 2014;9(4):e95043.

28. Kim YH, Kim JH, Choi YW, et al. Gankyrin is frequently overexpressed in breast cancer and is associated with ErbB2 expression. Exp Mol Pathol. 2013;94(2):360-365.

29. Zhang J, Yang Y, Zhang Z, et al. Gankyrin plays an essential role in estrogen-driven and GPR30-mediated endometrial carcinoma cell proliferation via the PTEN/PI3K/AKT signaling pathway. Cancer Lett. 2013;339(2):279-287.

30. Meng Y, He L, Guo X, et al. Gankyrin promotes the proliferation of human pancreatic cancer. Cancer Lett. 2010;297(1):9-17.
OncoTargets and Therapy

\section{Publish your work in this journal}

OncoTargets and Therapy is an international, peer-reviewed, open access journal focusing on the pathological basis of all cancers, potential targets for therapy and treatment protocols employed to improve the management of cancer patients. The journal also focuses on the impact of management programs and new therapeutic agents and protocols on

\section{Dovepress}

patient perspectives such as quality of life, adherence and satisfaction The manuscript management system is completely online and includes a very quick and fair peer-review system, which is all easy to use. Visit http://www.dovepress.com/testimonials.php to read real quotes from published authors. 